surface published in your last Number. Let me add that the striations, though rightly rendered as to direction in that lithograph, are not given with sufficient fineness or regularity. I may refer your readers to the plates of Scaphaspis Lloydii and the restorations of the shield of Pteraspis in my monograph for accurate reproduction. of striations having the same character as those of Holaspis. It is especially with Seaphaspis that Holaspis agrees in the form and size of its skin-like grooving.

E. RAY ILAKKESTHE.

OxFORD, June 18th.

\title{
GEOLOGICAL PROBLEMS.
}

SrR,-The following methods of finding by diagram, in place of calculation, certain data for the construction of correct geological sections, may be found useful.

Problem 1.-To find the apparent angle in any required section from the full dip, and the deviation of its direction from that of the section.

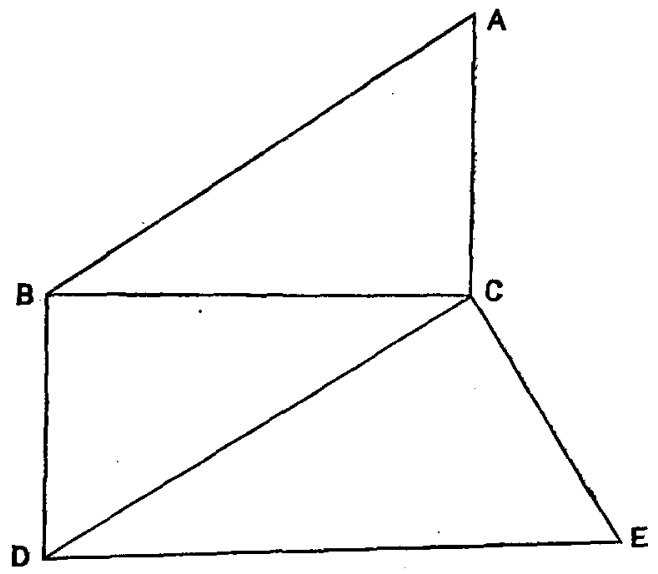

Constract the right-angled triangle $A B C$, with $A B C$ equal to the full dip; also the right-angled triangle $B C D$, with $B C D$ equal to the deviation; lastly the right-angled triangle $C D E$, in which $C E$ is equal to $A C$.

Then $C D E$ is the required apparent angle.

Proof--If $A B C$ be a vertical plane along the full dip, and $C D E$ the vertical plane of section. $B C D$ will be a horizontal plane, and $A C, C E$ will coincide, so that $B D, A E$ will be the plane of stratifcation, giving the apparent angle $C D E$ along the section.

Problem 2.-From two apparent dips ${ }^{1}$ to find the full dip and its direction.

1 Any three points, not being in a straight line, on a line of out-crop, will furnish 
Suppose two apparent dips, $41^{\circ}$ N.W. and $33^{\circ}$ N., $30^{\circ} \mathrm{E}$.

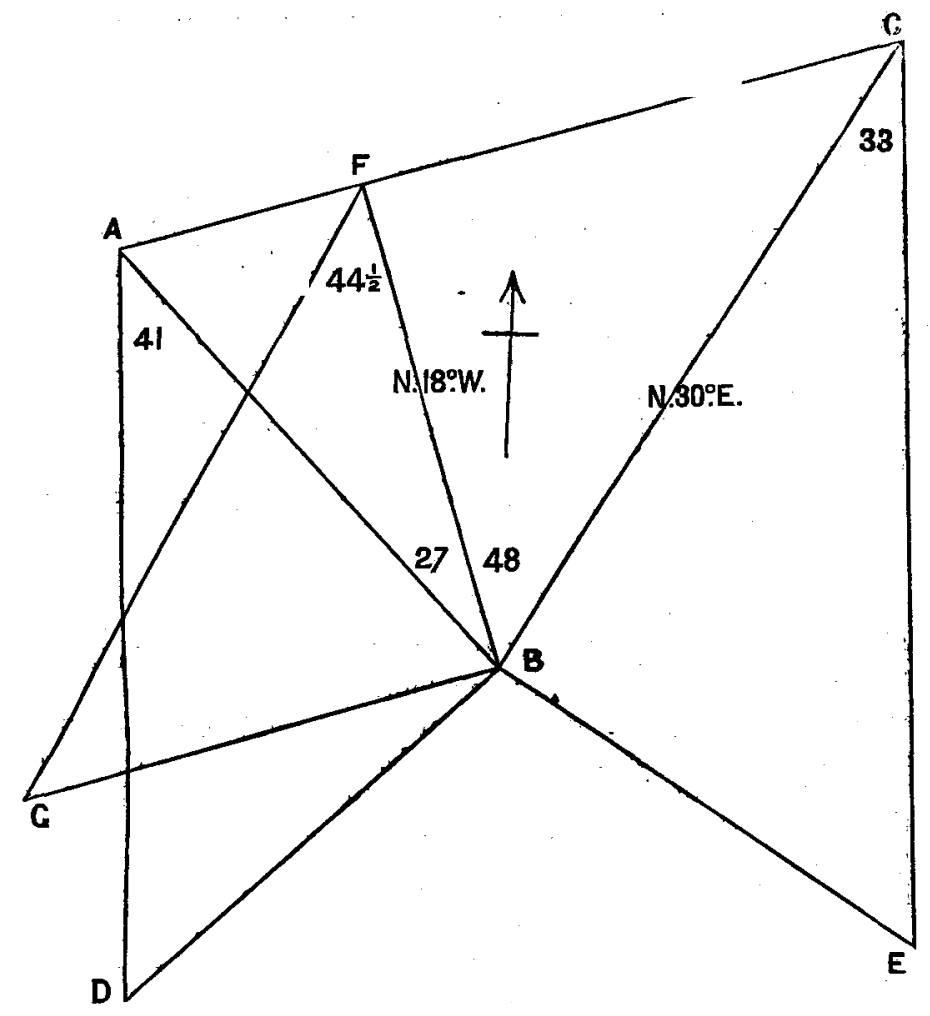

Result $44 \frac{1}{2}^{\circ} \mathrm{N} .18^{\circ} \mathrm{W}$.

Draw $B A, B C$ in the directions of the apparent dips : erect $B D$, $B E$ vertical to $B A, B C$ respectively, and equal to each other. From $D, E$, draw $D A, E C$, making $B A D, B C E$ equal to the apparent angles whose direction is shown by $B A, B C$ respectively. Join $A C$, and draw $B F$ vertical to it. Draw $B G$ parallel to $A C$, and equal to $B E$ : join $F G$.

Then $B F$ is the direction of the full dip and $G F B$ its amount.

Proof.-If $A B C$ be placed horizontally and $A B D, B C E, B F G$, vertically; $D, G$, and $E$ will coincide, and $D A, G F, E C$, and $A C$ will be in the plane of stratification giving the apparent angles at $A$ and $C$ and the full dip at $F$. In practice the triangle $B G F$ might be more expeditiously constructed between $B F^{\prime}$ and $A C$.

Problem 3.-Given a plane's dip and direction, to ascertain the effect on it of a secondary till of known amount and direction, and

three apparent dips, which may be taken two and two, thereby proving whether or no the stratum is a true plane, and if not, the mean of the three results will indicate the general dip. 
on the other hand from the present position of the plane to calculate its original dip.

1st. Find by problem 1 the dip of the plane in the direction $(a)$ of the secondary tilt and $(b)$ of its strike.

2nd. Add or subtract (as the case may require) to or from (a) the amount of the secondary tilt $(n)$.

3rd. From $a+n$ and $b$ (two apparent angles) find the full dip and its direction by Problem 2.

Example.-A plane dips N. at $50^{\circ}$, and is subsequently tilted $49^{\circ}$ to W. $30^{\circ} \mathrm{S}$. Find its final position. Its original dip to W. $30^{\circ} \mathrm{S}$. by Prob: 1 , is by diagram $-30^{3}$, by logarithms - $30^{\circ} 47^{\prime}$ (being that amount to E. $30^{\circ} \mathrm{N}$.) and to N. $30^{\circ}$ W., $453^{\circ}{ }^{\circ}$ (logs. $\left.45^{\circ} 54^{\prime}\right)$.

After the secondary tilt the dips are W. $30^{\circ} \mathrm{S} .181^{\circ}\left(49-30 \frac{9}{4}\right)$ and N. 30 W. $45 \frac{3}{4}$.

The resultant position being $47^{\circ}$ to $\mathrm{W} .42^{\circ} \mathrm{N}$. or by logs. $47^{\circ} 17^{\prime}$ to $\mathrm{W} .42^{\circ} 19^{\prime} \mathrm{N}$.

W. H. Dalton, H.M. Geol. Survey.

\section{LABYRINTHODONTS OF THE COAL-MEASURES.}

Srr,-At the last meeting of the British Association, in August, 1872, the following resolution was adopted:

“'That Professor Phillips, Professor Harkness, Mr. Henry Woodward, Mr. James Thomson, and Mr. L. C. Miall be a Committee for the purpose of investigating and reporting upon the Labyrinthodonts of the Coal-measures; and that Mr. L. C. Miall be the Secretary."

The Committee has entered upon its work, and it is hoped that useful results will be laid before the Association from time to time. It has become clear that the preliminary investigation at least must not be limited to British Carboniferous Labyrinthodonts, but must include the Triassic genera as well as the Carboniferous examples discovered in other countries. The successful prosecution of the inquiry is therefore found to depend in part upon the assistance which can be rendered by geologists resident in different parts of the world.

I am instructed by the Committee to inquire whether you can aid is in any way. Casts and photographs of instructive specimens, drawings, if practicable, of full size, and measurements of such parts as can be clearly identified, would be specially valuable. The Committee will further be glad to receive any publications bearing on the subject, which may not be readily accessible in England.

Pheosophicar Hail,
Imems, May, 1873. 